Supporting information

\title{
Molecular level Understanding of the Factors Affecting the Stability of Dimethoxy Benzene Catholyte Candidates from First principles Investigations
}

Rajeev S. Assary ${ }^{\mathrm{a}, \mathrm{b} *}$, Lu Zhang ${ }^{\mathrm{a}, \mathrm{c}}$, Jinhua Huang, ${ }^{\mathrm{a}, \mathrm{c}}$, Larry A. Curtiss' ${ }^{\mathrm{a}, \mathrm{b}}$

a) Joint Center for Energy Storage Research, Argonne National Laboratories, Argonne, IL, USA, 60439

b) Materials Science Division, Argonne National Laboratory, Argonne, IL, USA, 60439

c) Chemical Sciences and Engineering Division, Argonne National Laboratory, Argonne, IL, USA, 60439

*: corresponding author

RSA. Email: assary@anl.gov, Tel: 630-252-3536, Fax: 630-252-9555 


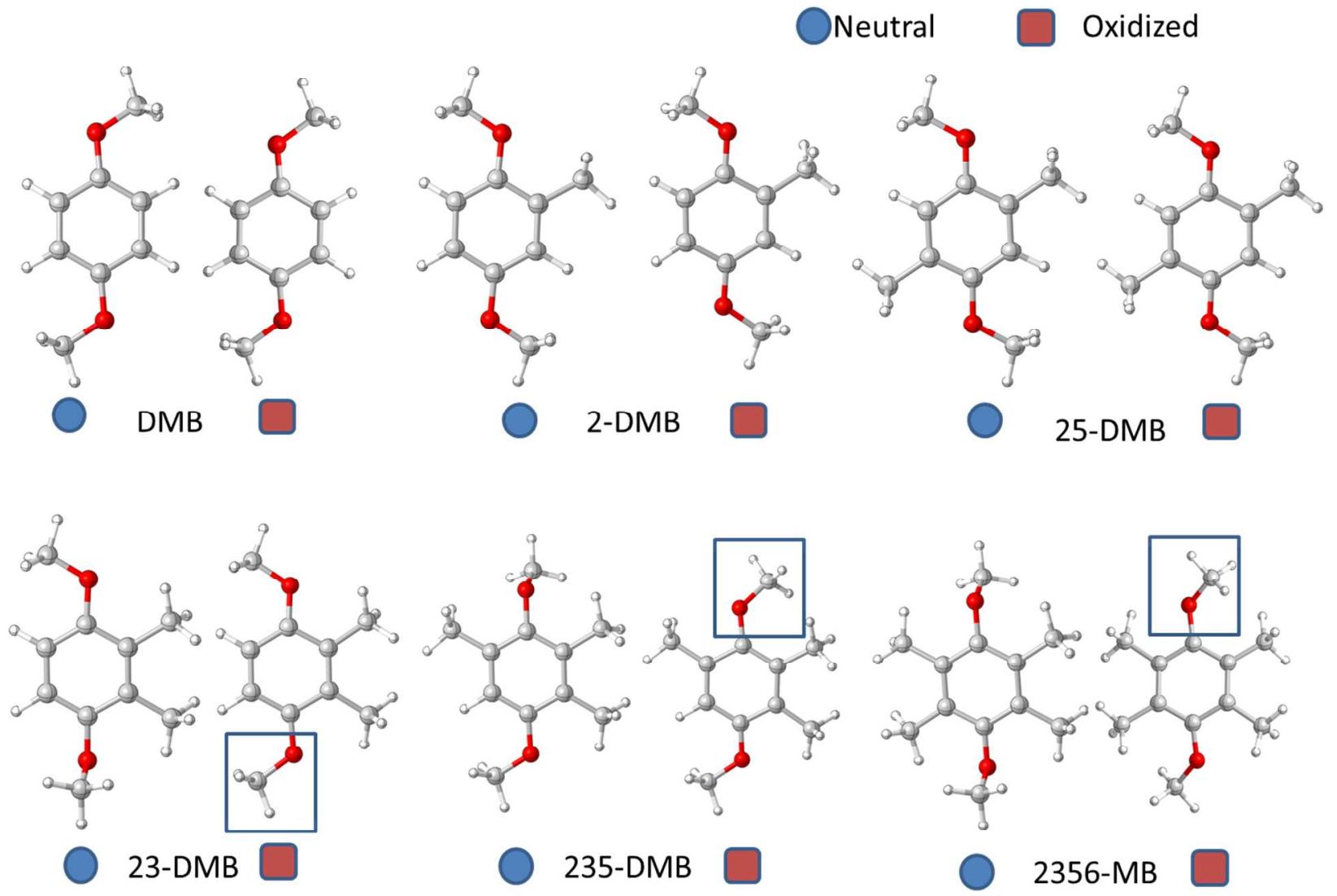

Figure S 1. Optimized geometries of selected neutral and cationic DMB derivatives at the B3LYP/6-31G(2df,p) level of theory. Selected structural parameters are shown in Table S1.

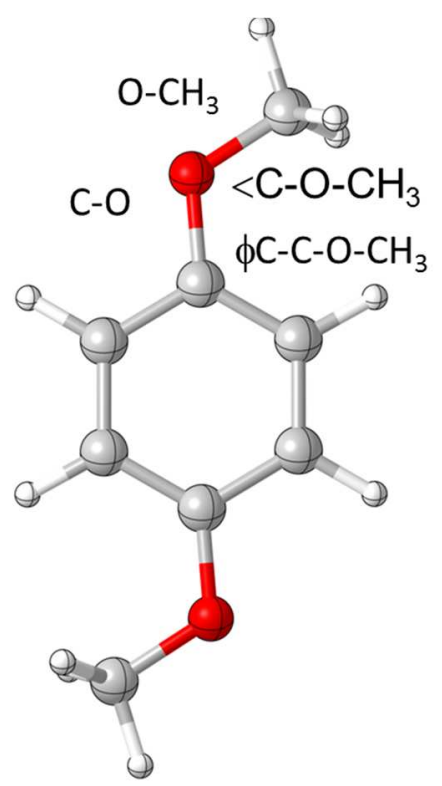

Figure S 2. Schematic of selected structural parameters of the DMB molecule (C-O: bond length, O-CH3: bond length, <C-O$\mathrm{CH}_{3}$ : bond angle, $\phi \mathrm{C}-\mathrm{C}-\mathrm{O}-\mathrm{CH} 3$ : dihedral angle). These parameters for all DFT-optimized DMB derivatives are tabulated in Table S1. 


\begin{tabular}{|c|c|c|c|c|c|}
\hline Species & & & & & \\
\hline \multirow[t]{2}{*}{ DMB } & Neutral & 1.37 & 1.43 & 118.3 & 180 \\
\hline & Cation & 1.32 & 1.45 & 121.3 & 180 \\
\hline \multirow[t]{2}{*}{ 2-DMB } & Neutral & 1.37 & 1.42 & 118.4 & 180 \\
\hline & Cation & 1.32 & 1.45 & 121.4 & 180 \\
\hline \multirow[t]{2}{*}{ 23-DMB } & Neutral & 1.37 & 1.43 & 114.4 & -178 \\
\hline & Cation & 1.32 & 1.45 & 121.6 & -180 \\
\hline \multirow[t]{2}{*}{ 25-DMB } & Neutral & 1.37 & 1.42 & 118.5 & 180 \\
\hline & Cation & 1.32 & 1.45 & 121.1 & 180 \\
\hline \multirow[t]{2}{*}{ 26-DMB } & Neutral & 1.39 & 1.43 & 114.8 & 85 \\
\hline & Cation & 1.32 & 1.45 & 128.3 & 10.1 \\
\hline \multirow[t]{2}{*}{ 235-DMB } & Neutral & 1.39 & 1.43 & 114.6 & 86.7 \\
\hline & Cation & 1.33 & 1.45 & 126.8 & 24.5 \\
\hline \multirow[t]{2}{*}{ 2356-DMB } & Neutral & 1.39 & 1.43 & 114.3 & -91.1 \\
\hline & Cation & 1.33 & 1.45 & 125.5 & -149.1 \\
\hline
\end{tabular}

Table S 1. Computed structural parameters (See Figure S1 and S2) of optimized neutral and cationic forms of DMBderivatives.

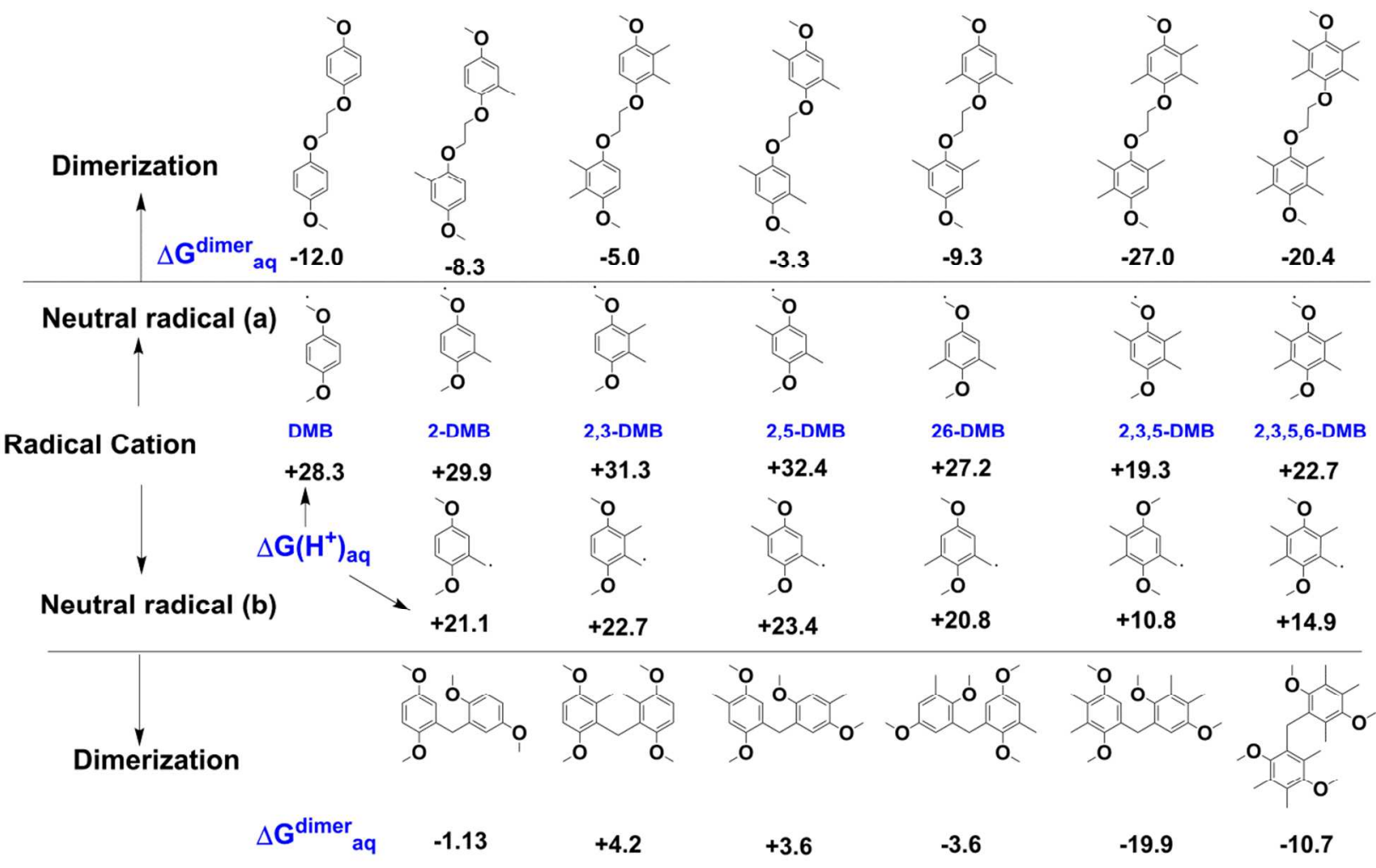

Figure S 3 Computed deprotonation energies (rxn 1 of Figure 5) and dimerization energies (rxn 4 of the figure 5) of radical cations at the B3LYP/6-31G(2df,p) level of theory. Solvent effects are approximated using the SMD solvation model with water dielectric model. All energies $(\mathrm{kcal} / \mathrm{mol})$ are with respect to the radical cation. 


\begin{tabular}{lcccc}
\hline Species & $\Delta \mathbf{H}^{\ddagger}(\mathbf{k c a l} / \mathrm{mol})$ & \multicolumn{3}{c}{$\Delta \mathbf{G}^{\ddagger}(\mathrm{kcal} / \mathrm{mol})$} \\
\cline { 2 - 5 } DMB & Water & Diethyl ether & Water & Diethyl ether \\
2-DMB & 26.7 & 23.6 & 36.1 & 33.0 \\
$23-D M B$ & 26.5 & 23.8 & 35.5 & 32.8 \\
$25-D M B$ & 27.2 & 24.7 & 36.6 & 34.1 \\
$26-D M B$ & 27.9 & 25.6 & 37.0 & 34.8 \\
$256-D M B$ & 23.8 & 21.0 & 34.6 & 31.8 \\
2356-DMB & 16.5 & 13.9 & 25.3 & 22.7 \\
\hline
\end{tabular}

Table S 2. Computed enthalpies and free energies of activation of demethylation reactions in water and diethyl ether dielectric media. 